\title{
Detection of RHD zygosity in China: using Syber Green I real-time polymerase chain reaction based on high-resolution melting curve analysis
}

\author{
Minyu Zhou ${ }^{1}$, Zhiyuan $\mathrm{Xu}^{2}$, Jingyan Chang ${ }^{3}$, Xiaojie Zhu ${ }^{4}$, Yu-Shiang Lin ${ }^{4 *}$ \\ ${ }^{1}$ Center of Laboratory Medicine, Foshan Hospital of Traditional Chinese Medicine, Foshan 528000, Guangdong, China; \\ ${ }^{2}$ Blood Group Lab, Beijing Red Cross Blood Center, Beijing 100088, China; \\ ${ }^{3}$ Department of Clinical Transfusion, Shaanxi Provincial People's Hospital, Xi'an 710000, Shaanxi, China; \\ ${ }^{4}$ Nobel Prize Research Institute, ZOJIWAT Biological Pharmaceutical Co. Ltd., Jiangyin 214400, Jiangsu, China
}

\begin{abstract}
Due to relatively higher mutation frequencies in Chinese individuals with the RHD-negative phenotype[25\% for 1227 G>A RHD elution and 5\% for RHD1-RHCE(2-9)-RHD10], Rhesus box analysis is rarely used in China. Here, quantitative real-time polymerase chain reaction (qPCR) with a high-resolution melting curve mode and a matrix mix containing Syber Green I were used to sequence specific primers of $1227 \mathrm{G}>\mathrm{A}$ and RHD exons 1, 5, and 10 in two families, consisting of two parents and two children per family $(n=8)$. The samples with RHD gene deletion homozygous/heterozygous, $1227 \mathrm{G}>\mathrm{A}$ heterozygous with RHD gene deletion and normal RHD, normal RHD homozygous/heterozygous, and RHDl-RHCE(2-9)-RHD10 homozygous/heterozygous status were all included. All samples were screened using RHD exon genotyping, Sanger sequencing, and Rhesus box analysis. DNA sample quality was maintained at $68 \sim 72 \mathrm{ng} / \mu \mathrm{L}$, and $\mathrm{OD}_{260 / 280}$ at 1.7 1.9. The Tm ratio of RHD exon $1\left(87^{\circ} \mathrm{C}\right)$ to internal control $\left(77^{\circ} \mathrm{C}\right.$ ) was $2.49 \sim 2.67$ and 2.09 2.35 in subjects with RHD exon 1 homozygous and heterozygous, respectively; the Tm ratio of RHD exon $10\left(81^{\circ} \mathrm{C}\right)$ to internal control $\left(77^{\circ} \mathrm{C}\right)$ was $5.01 \sim 6.11$ and $3.34 \sim 4.31$ in subjects with RHD exon 10 homozygous and heterozygous, respectively; the Tm ratio of RHD exon $5\left(83^{\circ} \mathrm{C}\right)$ to internal control $\left(77^{\circ} \mathrm{C}\right.$ ) was 3.98 4.75, 3.02 3.45, and 0.03 in subjects with RHD exon 5 homozygous, heterozygous, and deletion homozygous, respectively; the Tm ratio of $1227 \mathrm{~A}\left(87^{\circ} \mathrm{C}\right)$ to internal control $\left(77^{\circ} \mathrm{C}\right)$ was $1.11,0.51$, and $<0.03$ in subjects with 1227A heterozygous, 1227A homozygous (exon 9 deletion), and wild type, respectively. The results suggest that using the primers of Tm ratio in comparison with an internal control is an effective way to detect RHD gene deletion or RHD-RHCE hybrid variant allele carrier. The method can also be used to calculate the mother-newborn RHD phenotype proportion and assist pedigree analysis.
\end{abstract}

Keywords: RHD allele, high resolution melting curve, heterozygous, qPCR

\section{INTRODUCTION}

The D-negative phenotype frequency in Chinese individuals is estimated to be $0.27 \% \sim 0.59 \%^{[1-3]}$. In contrast, the most common cause of the D-phenotype in people of European origin is homozygous for a complete deletion of RHD. According to reports, the frequency of the RHD variant allele in Chinese individuals with D-phenotype was $74.1 \%, 20.2 \%$, and $5.6 \%$ for RHD gene deletion, $1227 \mathrm{G}>\mathrm{A}$ (RHD elution), and RHD1-RHCE(2-9)-RHD10, respectively ${ }^{[4,5]}$.

Rhesus box analysis is useful for detecting RHD

*Correspondence to: Yu-Shiang Lin, Nobel Prize Research Institute, ZOJIWAT Biological Pharmaceutical Co. Ltd., Jiangyin 214400, Jiangsu, China. E-mail:1448639963@qq.com.

Conflict of interests: The authors declared no conflict of interests. 
gene deletion homozygosity or hemizygosity because RHD gene deletion occurs in the Rhesus box ${ }^{[6]}$. However, Rhesus box analysis only determines $60 \%$ of RHD phenotypes. Shao et al. demonstrated that the $\mathrm{d}$ frequency was $5.6 \%$; D, 94.3\%; and Dd heterozygosity, $10.6 \%$ through Rhesus box analysis. The adjusted rate of Dd heterozygosity was $9.0 \%$ after excluding DEL (IAT-negative $)^{[7,8]}$. In contrast, we estimate that $>15.6 \%$ of all RHD variant alleles cannot be determined using Rhesus box analysis. For example, if one parent has the $\mathrm{RHD}^{-}$phenotype and the other is the $\mathrm{RHD}^{+}$phenotype, the proportion of $\mathrm{RHD}^{-}$in their child could be $50 \%$ to $10.6 \%$, with only $3.7 \%$ determinable using the Rhesus box.

Our study aimed to develop a cost-effective relative quantitative genotyping method that uses quantitative real-time PCR (qPCR) with a high-resolution melting(HRM) curve mode and sequence-specific primers and a matrix mix containing Syber Green I . The study detected prospectively the different allele combinations of RHD gene deletion, RHDl-RHCE (2-9)-RHD10, and $1227 \mathrm{G}>\mathrm{A}$.

\section{MATERIALS AND METHODS}

\section{Subjects}

Eight participants consisting of two generations of two unrelated families were enrolled in our study; all four parents had the $\mathrm{RHD}^{+}$phenotype, while the two sets of children had the RHD ${ }^{-}$phenotype in each family. For RHD serotyping and DNA extraction, $2 \mathrm{~mL}$ of ethylene diamine tetraacetic acid (EDTA) containing peripheral venous blood was used. Phenotyping involved the use of monoclonal $\mathrm{IgG} / \mathrm{IgM}$ mixed anti-D antibody(IgM clone: D175-2, and IgG clone: D4151E4, Novaclone, Dominion Biologicals Ltd., Dartmouth, Nova Scotia, Canada). The study was conducted in accordance with the current version of the Declaration of Helsinki.

\section{Genotyping and Sanger sequencing of RHD exons}

DNA was isolated from EDTA-anti-coagulated blood using a commercial kit (magnetic bead whole blood DNA extraction kit, Jiangsu ZhongjiWantai Biological Pharmaceutical Co. Ltd., Jiangsu, China) based on magnetic separation in an automated system (FluoVia Gene Pure Plus, Jiangsu ZhongjiWantai Bio logical Pharmaceutical Co. Ltd.). The quality of DNA samples was maintained at 68 72 $\mathrm{ng} / \mu \mathrm{L}$, and $\mathrm{OD}_{260 / 280}$ at 1.7 1.9.

Due to RHD gene deletion, $1227 \mathrm{G}>\mathrm{A}$, and RHDlRHCE (2-9)-RHD10 being the major RHD ${ }^{-}$phenotypes in Chinese individuals, we used the commercial kit (RH genotyping, Jiangsu ZhongjiWantai Bio logi- cal Pharmaceutical Co. Ltd.) to detect the RHD exons, $1227 \mathrm{G}>\mathrm{A}, 845 \mathrm{G}>\mathrm{A}$, and RHCE genotyping through qPCR (FluoVia Line Gene 900 plus, Jiangsu ZhongjiWantai Bio logical Pharmaceutical Co. Ltd.). Rhesus box analysis was used, as per the protocol published previously $^{[6]}$.

Sanger sequencing of RHD exons 1 to 10 was performed using a commercial RHD gene sequencing kit (RHD exon sequence; Jiangsu ZhongjiWantai Biological Pharmaceutical Co. Ltd.). Sanger sequencing of PCR-purified products was performed by Sangon Biotech (Shanghai, China), and the results were analyzed using sequence analysis software (Geneious R9; Auckland, New Zealand).

\section{HRM analysis assay design}

High-resolution melting curve analysis assay was performed using the FluoVia Line Gene 900 plus. Primers and matrix mix were processed using a commercial kit(RH genotyping, Jiangsu ZhongjiWantai Bio logical Pharmaceutical Co. Ltd.). The quality of the DNA samples was maintained at 68 72 $\mathrm{ng} / \mu \mathrm{L}$, and $\mathrm{OD}_{260 / 280}$ at $1.7 \sim 1.9$, respectively, and the final DNA concentration in the $10 \mu \mathrm{L}$ matrix $\operatorname{mix}$ was $6.2 \sim 6.5 \mathrm{ng} / \mu \mathrm{L}$.

\section{Tm ratio calculating}

We used the following formula to calculate the Tm ratio of alleles of RHD exon 1, 5, 10, and 1227A and the internal control to determine homozygosity, hemizygosity, and heterozygosity.

The highest $\mathrm{Tm}$ of positive curve area

(RHD exon 1 between $86-88^{\circ} \mathrm{C}$ or RHD exon 5 between $82-84^{\circ} \mathrm{C}$ or RHD exon 10 between $80-82^{\circ} \mathrm{C}$ or RHD 1227 between $86-88^{\circ} \mathrm{C}$ )

The highest $\mathrm{Tm}$ of internal control area $\left(76-78^{\circ} \mathrm{C}\right)$

\section{RESULTS}

\section{Baseline of subjects}

Pedigree analysis was performed by phenotyping, genotyping, and sequencing of two Chinese families. The first family was $1227 \mathrm{G}>\mathrm{A}$ carrier and RHD gene deletion carrier in the first generation, while their first child was $1227 \mathrm{G}>\mathrm{A} / \mathrm{RHD}$ gene deletion, and their second child had normal RHD homozygous. The second family was RHDI-RHCE(2-9)-RHD10 carrier and RHD gene deletion carrier in the first generation, while their first child had RHD1-RHCE(2-9)-RHD10 /RHD gene deletion, and their second child was normal RHD homozygous (Fig. 1 and Table 1). 


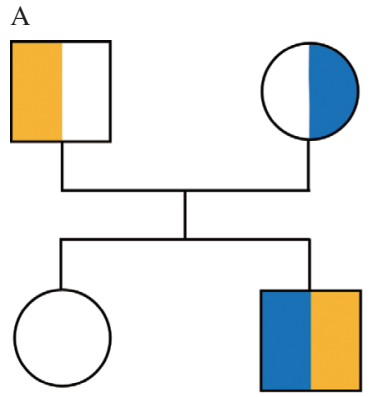

B

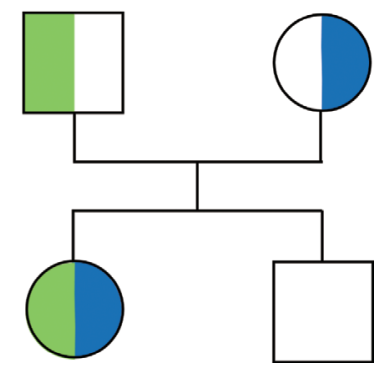

Fig. 1 Pedigree analysis of $\mathrm{RHD}^{+}$phenotype parents with $\mathrm{RHD}^{-}$phenotype children in two Chinese families (A, B). Yellow, blue, and green geometries indicated $1227 \mathrm{G}>\mathrm{A}$ allele, RHD gene deletion, and RHD1-RHCE (2-9)-RHD10, respectively.

\section{HRM analysis}

The Tm ratio of RHD exon $1\left(87^{\circ} \mathrm{C}\right)$ to internal control $\left(77^{\circ} \mathrm{C}\right)$ was $2.49 \sim 2.67$ and $2.09 \sim 2.35$ in subjects with RHD exon 1 homozygous and heterozygous, respectively; the Tm ratio of RHD exon $10\left(81^{\circ} \mathrm{C}\right)$ to internal control $\left(77^{\circ} \mathrm{C}\right)$ was $5.01 \sim 6.11$ and $3.34 \sim 4.31$ in subjects with RHD exon 10 homozygous and heterozygous, respectively; the Tm ratio of RHD exon $5\left(83{ }^{\circ} \mathrm{C}\right)$ to internal control $\left(77^{\circ} \mathrm{C}\right)$ was $3.98 \sim 4.75$ and $3.02 \sim 3.45$ in subjects with RHD exon 5 homozygous and heterozygous, respectively, and 0.03 in subjects with RHD exon 5 deletion homozygous; the $\mathrm{Tm}$ ratio of $1227 \mathrm{~A}\left(87^{\circ} \mathrm{C}\right.$ ) to internal control $\left(77^{\circ} \mathrm{C}\right)$ was $1.11,0.51$, and $<0.03$ in subjects with 1227A heterozygous, 1227A homozygous (exon 9 deletion), and wild type (Table 2 and Fig. 2).

Table 1 Result of RHD phenotyping, genotyping, and sequencing in the members of two Chinese families

\begin{tabular}{|c|c|c|c|c|c|}
\hline ID & RHD phenotype & RHD exon genotyping & RHD exon sequence & Rhesus box & Allele \\
\hline Fatherl & $\mathrm{RHD}^{+}$ & RHD exon $1-10$ exist, $1227 \mathrm{G}>\mathrm{A}$ & $1227 \mathrm{G}>\mathrm{A}$ heterozygous & $\mathrm{RHD}^{+} / \mathrm{RHD}^{+}$ & Normal RHD/1227A \\
\hline Motherl & $\mathrm{RHD}^{+}$ & RHD exon $1-10$ exist & Normal RHD & $\mathrm{RHD}^{+} / \mathrm{RHD}^{-}$ & Normal RHD/RhD gene deletion \\
\hline Daughterl & $\mathrm{RHD}^{+}$ & RHD exon 1-10 exist & Normal RHD & $\mathrm{RHD}^{+} / \mathrm{RHD}^{+}$ & Normal RHD/ Normal RHD \\
\hline Sonl & $\mathrm{RHD}^{-}$ & RHD exon $1-10$ exist, $1227 \mathrm{G}>\mathrm{A}$ & $1227 \mathrm{G}>\mathrm{A}$ homozygous & $\mathrm{RHD}^{+} / \mathrm{RHD}^{-}$ & 1227A/RhD gene deletion \\
\hline Father2 & $\mathrm{RHD}^{+}$ & RHD exon 1-10 exist & Normal RHD & $\mathrm{RHD}^{+} / \mathrm{RHD}^{+}$ & $\begin{array}{l}\text { Normal RHD/ RHD1-RHCE } \\
(2-9)-R H D 10^{*}\end{array}$ \\
\hline Mother2 & $\mathrm{RHD}^{+}$ & RHD exon 1-10 exist & Normal RHD & $\mathrm{RHD}^{+} / \mathrm{RHD}^{-}$ & Normal RHD/ RHD gene deletion \\
\hline Daughter2 & $\mathrm{RHD}^{-}$ & $\begin{array}{l}\text { RHD exon 1,10 exist; } \\
\text { RHD exon 2-9 absent }\end{array}$ & $\begin{array}{l}\text { RHD exon } 1,10 \text { normal, } \\
\text { RHD exon } 2-9 \text { absent }\end{array}$ & $\mathrm{RHD}^{+} / \mathrm{RHD}^{-}$ & $\begin{array}{l}\text { RHD1-RHCE(2-9)-RHD10/ } \\
\text { RhD gene deletion }\end{array}$ \\
\hline Son2 & $\mathrm{RHD}^{+}$ & RHD exon 1-10 exist & Normal RHD & $\mathrm{RHD}^{+} / \mathrm{RHD}^{+}$ & Normal RHD/ Normal RHD \\
\hline
\end{tabular}

- Depending on the pedigree analysis of his daughter with RHD1-RHCE (2-9)-RHD10/RHD gene deletion.

Table 2 Consistency between genotyping and monoclonal antibody typing in 23 samples with or without transfusion history

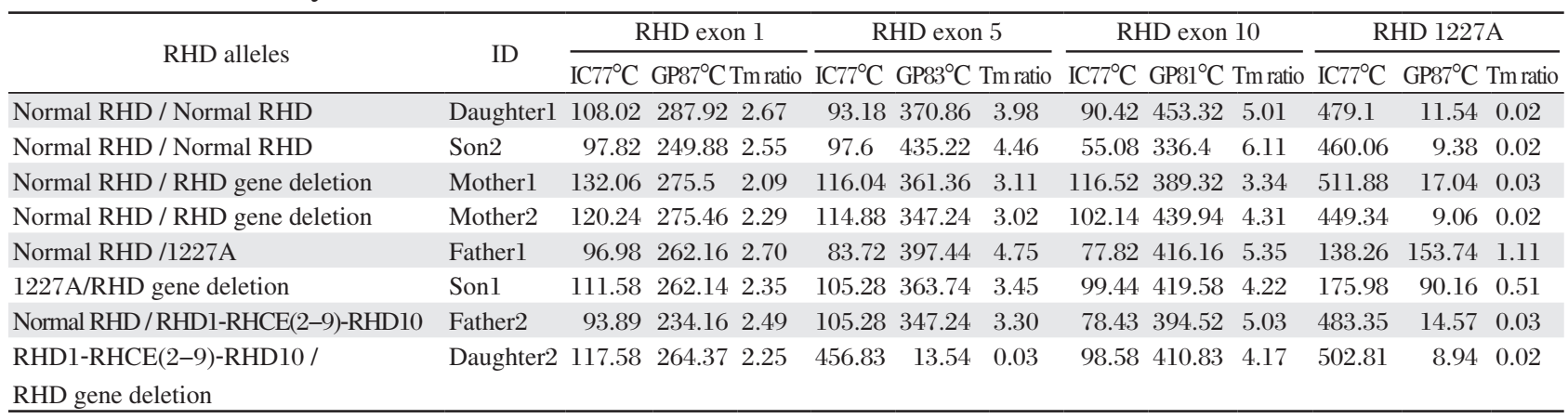

IC: internal control; GP: greatest positive

\section{DISCUSSION}

This study was the first to use the HRM mode to analyze the RHD genotype's allele status. The method may assist gynaecology, medical genetics, and transfusion to estimate the patient's RHD hereditary status. Especially, in pregnant women with RHD $^{-}$phenotype, the proportion of $\mathrm{RHD}^{-}$phenotype new-borns or foetuses still remain about $10 \%$, even the father has the $\mathrm{RHD}^{+}$ phenotype. This lack of a useful method to predict the RHD typing of new-borns is still a limit for predicting the risk for hemolytic disease of the new-born. Besides, in $\mathrm{RHD}^{-}$Chinese individuals, only $7 \%$ of individuals can be screened using Rhesus box analysis due to RHD gene deletion, while other $3 \%$ lack an examination to detect the RHD variant allele. In this study, the use of genotyping $\mathrm{Tm}$ ratio to internal control presents a plausible way of detecting relative high-frequency alleles, including 1227A and RHD-RhCE hybrid. 
Tm ratio of Exon1 to IC

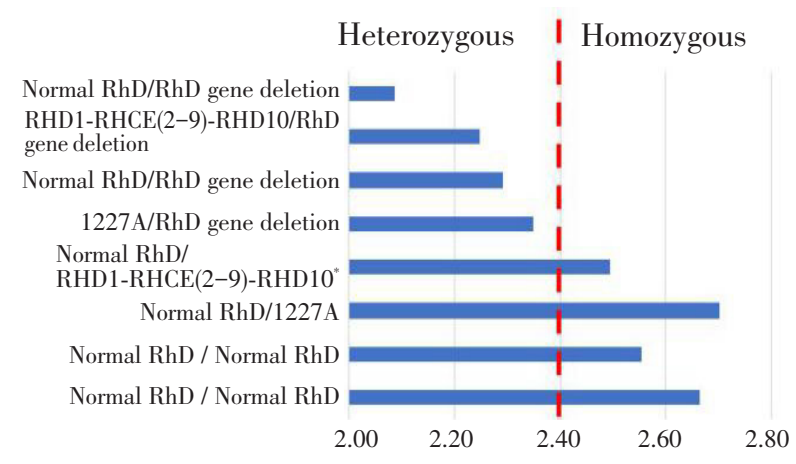

Tm ratio of Exon5 to IC

Gene deletion I Heterozygous IHomozygous
Tm ratio of Exon10 to IC

\section{Heterozygous I Homozygous}

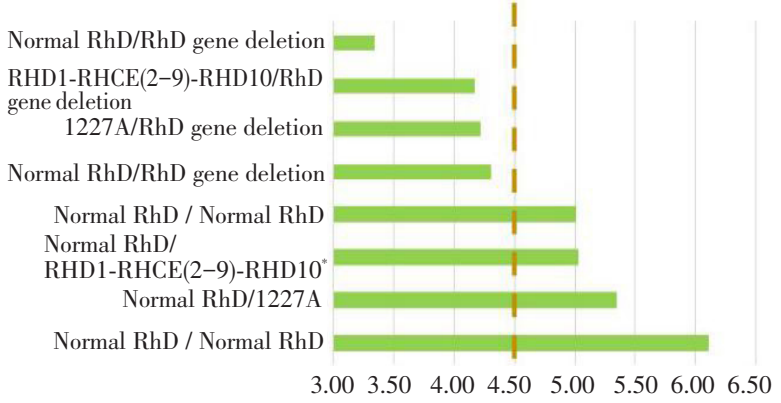

Tm ratio of $1227 \mathrm{~A}$ to IC

Wild type |Heterozygousl Homozygous
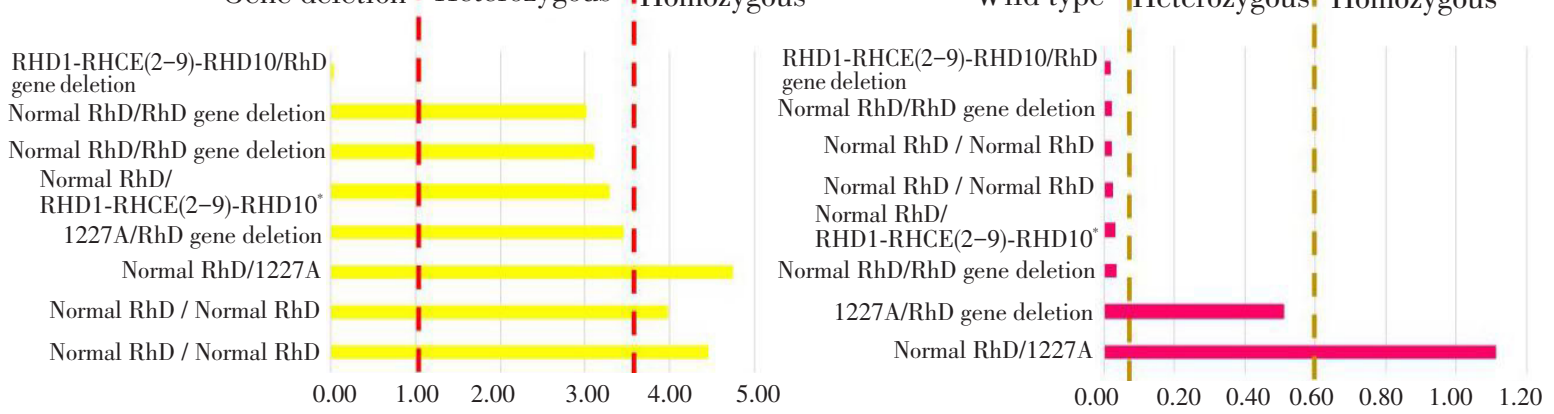

Fig. 2 The Tm ratio of sequence-specific primers of RHD exons 1, 5, 10, and 1227A to internal control in RHD allele homozygous, heterozygous, wild type, and gene deletion cases.

In China, several studies have discussed the frequencies of RHD allele in $\mathrm{RHD}^{-}$or variant phenotype and summarized that RHD gene deletion, RHD-RHCE (2-9)-RHD, and $1227 \mathrm{G}>\mathrm{A}$ were the most common alleles that cause the $\mathrm{RHD}^{-}$phenotype, while 845 $\mathrm{G}>\mathrm{A}$ (weak D15 or partial D12) was the major allele that causes weak D phenotype ${ }^{[9-11]}$. However, very few studies have investigated RHD allele combinations in the Chinese population. Lan et al. used Rhesus box analysis to present the $\operatorname{RHD}(+) / \operatorname{RHD}(-)$, and RHD (+)/ RHD (+) genotypes accounting for $9.0 \%$ and $91.0 \%$, respectively in $\mathrm{RHD}^{+}$phenotype individuals. Frequencies of $\operatorname{RHD}(+) / \operatorname{RHD}(-), \operatorname{RHD}(+) / \operatorname{RHD}(+)$, and RHD()/RHD(-) genotypes were $26.14 \%, 3.92 \%$, and $69.94 \%$, respectively in $\mathrm{RHD}^{-}$individuals. However, the result also only showed $3.92 \%$ in RHD (+) / RHD (+) and $13.07 \%$ (half of $26.14 \%$ ) in RHD (+) / RHD(-)from the RHD $^{-}$phenotype ${ }^{[12]}$. So, the frequency of RHD variant carriers with $\mathrm{RHD}^{+}$phenotype has not yet been estimated. Shao et al. reported on a Chinese Han woman who delivered an $\mathrm{RHD}^{-}$negative child at a rate of $3.7 \%$ 4.5\% despite both parents being $\mathrm{RHD}^{+[1]}$.

The molecular analysis used to determine the RHD variant in $\mathrm{RHD}^{-}$, or weakly positive phenotype is well documented ${ }^{[13]}$. However, to identify the allele in $\mathrm{RHD}^{+}$phenotype or decipher genotype data without phenotype data were very difficult. For example, in this study the genotype showed $1227 \mathrm{G}>\mathrm{A}$ with the presence of RHD 10 exons, for which $\mathrm{RHD}^{+}$and $\mathrm{RHD}^{-}$are both possible phenotypes. Because of the two alleles in the subject being $1227 \mathrm{G}>\mathrm{A}$, the other allele could be RHD gene deletion or RHD-RHCE(29)-RHD for $\mathrm{RHD}^{-}$phenotype or normal RHD for $\mathrm{RHD}^{+}$phenotype. The method of our study could be used to estimate the frequency of RHD-RHCE hybrid in $\mathrm{RHD}^{+}$Chinese individuals and predict the hazard ratio of RHD phenotype in Chinese parents. Our study also has some limitations: only the RHD-RHCE, 1227 $\mathrm{G}>\mathrm{A}$, and weak D15 were detected, and other known (or unknown) mutation alleles cannot be screened. Subsequent research could utilize a larger sample size and include RHD gene deletion homozygous, although sequence-specific primers aren't able to amplify RHD gene deletion specimens.

Using the Tm ratio of sequence-specific primer to internal control is an effective method to detect RHD gene deletion or an RHD-RHCE hybrid variant allele carrier. The method can also be used to calculate RHD phenotype proportion of parent-newborn and assist in pedigree analysis.

\section{References}

[1] Shao CP, Qin JJ, Sun GD, et al. An analysis of RHD 

based on high-resolution melting curve analysis, 2019, 3(1)

zygosity of RH(D)-positive Chinese Han population. Zhonghua Yi Xue Yi Chuan Xue Za Zhi(In Chinese), 2011, 28(1):29-32.

[2] Ye SH, Wu DZ, Wang MN, et al. A comprehensive investigation of RHD polymorphisms in the Chinese Han population in Xi'an. Blood Transfus, 2014,12(3):396404.

[3] Jiang X, Wu J, Wang Z, et al. Investigation of the distribution of $\mathrm{ABO}$ and $\mathrm{RH}$ blood groups in hospitalized patients in Xi'An Area. J Clin Hematol(In Chinese), 2018, 31(10): 757-9.

[4] Colin Y, Chérif-Zahar B, Le Van Kim C, et al. Genetic basis of the RHD-positive and RHD negative blood group polymorphism as determined by Southern analysis. Blood, 1991,78(10):2747-52.

[5] Yan F, Lin YS, Xu ZY, et al. Which RHD alleles are risk factors stimulating allo-anti-D? Asia-Pacific Journal of Blood Types and Genes, 2017, 1(3):29-32.

[6] Wagner FF, Flegel WA. RHD gene deletion occurred in the RHesus box. Blood, 2000,95(12):3662-8.

[7] Gu J, Wang XD, Shao CP, et al. Molecular basis of DEL phenotype in the Chinese population. BMC Med Genet, 2014,15:54.

[8] Huang J, Cong S, Zeng XJ, et al. The RHD zygosity in
Dong ethnic population in the southeast area of Guizhou province. Zhonghua Yi Xue Yi Chuan Xue Za Zhi(In Chinese), 2011,28(2):227-9.

[9] Hu B, Feng Z, Zhu Y. Polymorphism of RHD gene among RHD negative and D variant blood donors from Qingdao region. Zhonghua Yi Xue Yi Chuan Xue Za Zhi(In Chinese), 2017,34(6):897-900.

[10] Ye L, Wang P, Gao H, et al. Partial D phenotypes and genotypes in the Chinese population. Transfusion, 2012, $52(2): 241-6$.

[11] Xu W, Zhu M, Wang BL, et al. Prospective evaluation of a transfusion policy of RHD-positive red blood cells into DEL patients in China. Transfus Med Hemother, 2015,42(1):15-21.

[12] Lan JC, Zhou HY, Xia R, et al. A method for RHesus box test. Zhongguo Shi Yan Xue Ye Xue Za Zhi(In Chinese), 2005,13(6):1103-5.

[13] Sandler SG, Chen LN, Flegel WA. Serological weak D phenotypes: A review and guidance for interpreting the RHD blood type using the RHD genotype. Br J Haematol, 2017, 179(1): 10-19.

(Received 20 February 2019, Revised 28 April 2019, Accepted 08 May 2019) 


\section{Antibody}

安迪溥拮

\section{JiangSu LIBO Medicine Biotechnology Co.,Ltd.}

\section{Diagnosis of Hemolytic Disease of the Newborn}

\section{ABO、Rh(D) Antigen Testing Card Newborn}
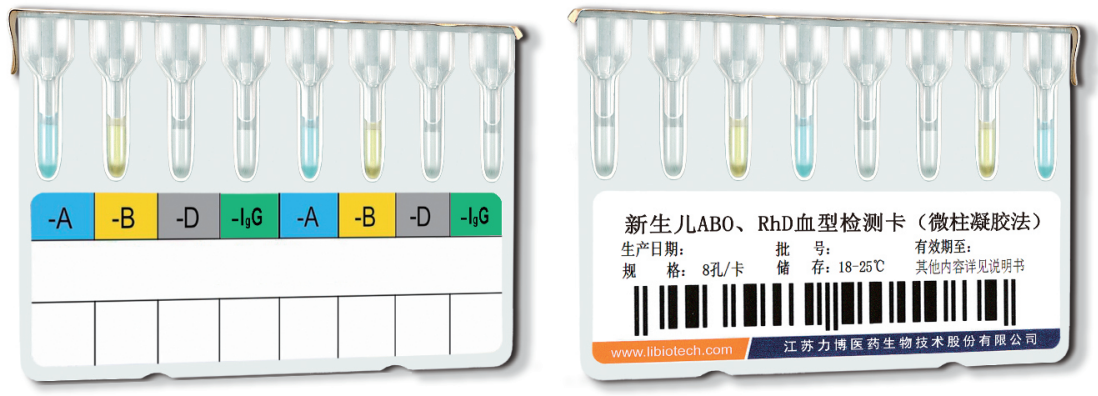

Intended Use :

The product is suitable for clinical tests on $\mathrm{ABO}$ and $\mathrm{Rh}(\mathrm{D})$ blood typing and direct antiglobulin test (DAT) for newborns and suspected hemolytic disease patients. It is only applicable for clinical test, but not for blood screening.

\section{Case :}
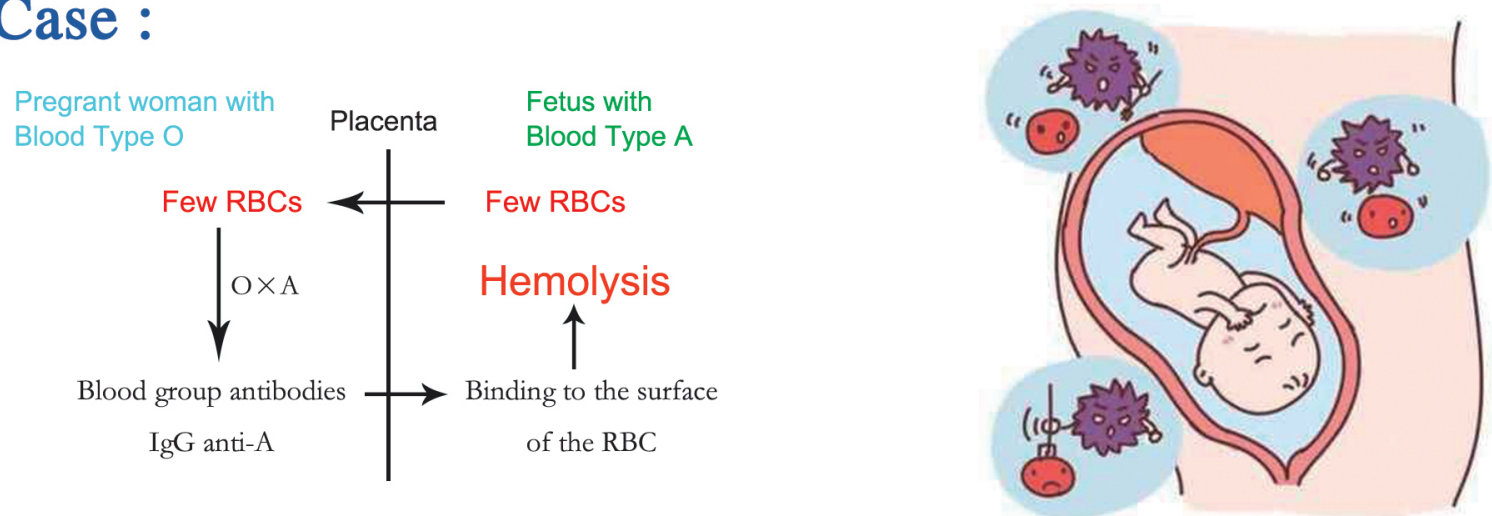

\section{Antibodl 安画溥君 \\ JiangSu LIBO Medicine Biotechnology Co.,Ltd.}

Address: No 78 West Dongsheng Road, Jiangyin, Jiangsu214400, P.R. China

Web Site: www.libiotech.com

Sales Tel: +86-510-86990618、+86-510-86990633

Tech Tel: +86-510-86990608、+86-510-86990655

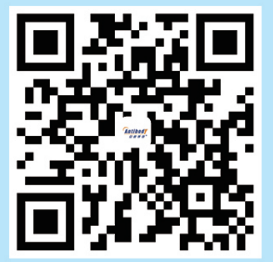

